\title{
ENRIQUE II DE CASTILLA EN LA LITERATURA ROMÁNTICA: LA SOMBRA DE PEDRO EL CRUEL
}

\author{
Noemi Catalán Romero \\ Universidad de Alicante
}

\begin{abstract}
RESUMEN
El presente estudio tiene como objetivo el análisis del tratamiento que realiza la literatura romántica de la figura de Enrique II de Castilla, teniendo en cuenta la relevancia de este personaje histórico como fundador de la dinastía de los Trastámara, cuyo origen está enmarañado en el telar de la bastardía y el fratricidio.
\end{abstract}

Palabras clave: Enrique II de Castilla, literatura romántica, siglo XIX.

\section{Abstract}

Analyzing the treatment about the figure of Enrique II of Castilla by Romantic Literature, is the aim of the following study. Needless to say that the was the forefather of Trastámara's dynasty, which complicated beginning was led by bastardy and fratricide.

KEY WORDS: Enrique II of Castilla, Romantic Literature, XIX century.

\section{INTRODUCCIÓN}

En la segunda mitad del siglo XIX se crea en España el Estado Liberal impulsado por la burguesía, que ante la nueva situación, se ve obligada a iniciar un proceso de legitimación en búsqueda de la definición de la identidad nacional. Es en tan ardua tarea donde comienza la mitificación del pasado. A ello contribuye no sólo la historiografía sino la propia literatura; nacía la novela histórica. A este respecto, los escritores románticos vuelcan sus plumas hacia el tintero de la tradición pues, no en vano, estaban ante una nación cultural y política. El pueblo, impulsado por el espíritu de Herder, se convertía en agente activo en el devenir histórico. 
Nacía así mismo un Romanticismo político cuyo vehículo fue la literatura, por ello la elección del personaje histórico no era una cuestión baladí.

En aparente contradicción los liberales identificaron el Estado con la Corona, de manera que en la literatura romántica aparecerán con profusión los monarcas, que sufrirán un proceso de humanización relacionado directamente con el individualismo romántico. La historiografía liberal de la segunda mitad del siglo sembrará dos de las características de la historiografía nacionalista: la idealización de la Edad Media, de ahí la gran pléyade de monarcas medievales existente en la literatura, y la idea del dominio de Castilla en la formación de la nación ${ }^{1}$, por lo que «la principal aportación de la literatura a la creación de la identidad nacional fue imaginar los ambientes de nuestro pasado» ${ }^{2}$.

Por otro lado, el contexto fue decisivo. La guerra civil desatada después de la muerte de Fernando viI causó la necesidad de la Historia como ejemplo, así pues, «los románticos, en realidad, intentaron sacar de la historia una lección de ejemplaridad»${ }^{3}$.

Los escritores románticos han tratado en sus obras a diversos monarcas de la dinastía Trastámara. Si bien Enrique II fue el precursor, antes de concluir el siglo XV se dará la unión dinástica de la Corona de Castilla y Aragón, suceso estrechamente vinculado al concepto de identidad nacional. Además, la dinastía está ligada al fortalecimiento del poder regio, lo que supone la creación de los cimientos de la monarquía hispánica.

El mundo de la corte intrigante de la dinastía era atractivo, teniendo en cuenta el contexto convulso de la primera mitad del siglo XIX.

Además, la Casa de Trastámara fomentaba la idea de unidad con halos providencialistas ya desde Enrique $\mathrm{II}^{4}$. Así mismo, Castilla se convierte en mito ${ }^{5}$ para los románticos, máxima expresión del liberalismo, llegándose a confundir la expansión de aquella con la de una dinastía concreta, una idea ya vigente en el padre Juan de

${ }^{1}$ E. I. Fox, «La invención de España: literatura y nacionalismo», en D. Flitter (coord.), Actas del XIII Congreso de la Asociación Internacional de Hispanistas, celebrado del 21 al 26 de Agosto de 1995 en Birmingham, vol. Iv (Del Romanticismo a la guerra civil), Birmingham, University of Department of Hispanic Studies, 1998, pp. 1-16.

${ }^{2}$ J. Álvarez Junco, Mater Dolorosa. La idea de España en el Siglo XIX, Madrid, Taurus, 2001, p. 242.

${ }^{3}$ M. Moreno Alonso, Historiografía romántica española. Introducción al estudio de la Historia en el siglo XIX, Sevilla, Servicio de Publicaciones de la Universidad de Sevilla, 1979, p. 63.

${ }^{4}$ R. García Cárcel, La herencia del pasado (Las memorias históricas de España), Barcelona, Galaxia Gutenberg, 2011, p. 512.

${ }^{5}$ P. Carasa, «La memoria histórica de Castilla y León. Introducción», en P. Carasa (coord.), La memoria histórica de Castilla y León (Historiografía castellana en los siglos XIX y XX, Valladolid, Junta de Castilla y León, 2003, p. 8. 
Mariana y luego aprovechada en el siglo XIX para articular el sentimiento nacional.

Para nuestro estudio es importante la relación que se estableció entre el Romanticismo y el liberalismo porque influye en el tratamiento que se dará a Enrique II, considerado como el campeón de la nobleza feudal, la misma que empezaba a decaer durante la minoría de edad de Isabel II. Así, hay autores ${ }^{6}$ que identifican los dos conceptos. Derek Flitter ${ }^{7}$, sin embargo, sostuvo que la asociación exclusiva entre ambos es insostenible, dado que lo que triunfó fueron los principios del historicismo europeo expuestos por los hermanos Schlegel. Guillermo Díaz-Plaja ${ }^{8}$ señala el triunfo del Romanticismo Liberal; por su parte, Guillermo Carnero ${ }^{9}$ destaca la influencia de Francisca Larrea.

Las contradicciones que supuso la explosión del liberalismo intentando conjugar los elementos de la Monarquía Constitucional repercutirán en el seno del Romanticismo. De ahí la existencia de un Romanticismo Histórico, reflejo de una sociedad monárquica y cristiana ${ }^{10}$ que hunde sus raíces en el siglo de Oro, y un Romanticismo revolucionario al estilo puramente francés. Derivado de ello fue el debate que se produjo entre clasicismo y Romanticismo y la asociación de este con el medievalismo y cristianismo, tal y como señaló Ramón López Soler desde las páginas de la revista El Europeo.

El enfoque que hemos seguido en este artículo es histórico-literario, dada la condición de histórico de nuestro personaje y la simbiosis que se dio entre Historia y Literatura. Por ello hemos aludido a diversas fuentes historiográficas ya que «los personajes y los acontecimientos son construidos como tales en y por la historiografía» ${ }^{11}$.

En cuanto al corpus de obras escogidas para el estudio de la imagen del rey Enrique, las citadas son las únicas que hemos hallado en las que el monarca tiene cierto protagonismo, dado que es Pedro el Crue ${ }^{12}$ o figuras como Blanca de Borbón quienes

${ }_{6}^{6}$ J. L. Abellán, Historia del pensamiento español. De Séneca a nuestros días, Madrid, Espasa-Calpe, 1996, p. 355.

${ }^{7}$ D. Flitter, Teoría y Crítica del romanticismo español, Cambridge, Cambridge University Press, 1992, p. 5.

${ }^{8}$ G. Díaz-Plaja, Introducción al estudio del Romanticismo español, Madrid, Espasa-Calpe, 1972, p. 26.

${ }_{9}^{9}$ G. Carnero, «El teatro de Calderón como arma ideológica en el origen gaditano del Romanticismo español», Cuadernos de Teatro Clásico, 5 (1990), pp. 125-140. El autor destaca la influencia de su pensamiento ultraconservador en la querella calderoniana.

${ }^{10}$ Es el postulado, por ejemplo, por Alberto Lista.

${ }^{11}$ P. Cirujano Marín, T. Elorriaga Planes, J. S. Pérez Garzón, Historiografía y nacionalismo español (18341868), Madrid, Centro de Estudios Históricos, 1985, p. 181.

${ }^{12}$ Son muchas las obras que tienen como protagonista a Pedro el Cruel a pesar de que no figure su nombre en el título. A este respecto podemos recordar las novelas románticas El Primogénito de Alburquerque, de R. López Soler, El castellano o el Príncipe Negro en España, de T. de Trueba y Cossío, o los dramas 
ocupan el puesto de personaje principal. Hemos tratado al rey tanto en novela como en drama para comprobar si su imagen varía de un género a otro. Igualmente hemos analizado algún romance y leyenda.

Los dramas que hemos encontrado se sitúan en torno a la década de los 40, siendo escasas las piezas románticas en las que tiene protagonismo Enrique. Este periodo está relacionado con el auge romántico y el liberalismo, por ello es Pedro el Cruel quien destaca. Así mismo, hemos tratado algunas tragedias dada la relación que guardan con el drama romántico y el histórico. Es en este último donde destacará Enrique II.

En relación a la novela hemos acotado el espacio a la década de los 50, es en la llamada por Juan Ignacio Ferreras ${ }^{13}$ novela histórica de aventuras donde más presencia tiene el rey. Es en torno a1850-1860 donde se produce un cierto debilitamiento romántico, con la afirmación de la burguesía nacional se inicia el proceso de construcción del Estado y de la memoria histórica; la literatura se impregna de ideología. Hemos tenido, pues, en cuenta en el estudio de las obras el contexto histórico en el que se produjeron.

\section{ENRiQue II de CASTilla: el bastardo libertador}

Los escritores románticos escogieron de la dinastía a los monarcas cuyos reinados presentaban similitud con el presente, tenían ciertas taras biológicas o contribuían a reforzar la identidad nacional: Enrique III el Doliente ${ }^{14}$ fue muy tratado, entre otros motivos, por la pugna entre miembros de la nobleza, los Guzmanes, los Ponce de León y los Epígonos Trastámara; en Enrique IV ${ }^{15}$ confluían factores políticos, legendarios y personales. Pero son sin duda Juan II de Castilla y Juan II de Aragón quienes más atractivo tuvieron; el primero por los enfrentamientos entre Álvaro de Luna, los Infantes de Aragón y la nobleza castellana, y el segundo por su relación dramática con el Príncipe de Viana y Blanca de Navarra.

Hemos titulado nuestro ensayo de esta manera porque opinamos que la figura de Enrique II de Castilla en la literatura romántica estuvo eclipsada por la del rey Pedro

románticos Don Pedro el Cruel, de J. M. Huici, El zapatero y el rey, de J. Zorrilla. Fue protagonista además de los romances históricos del Duque de Rivas, personaje trágico en Blanca de Borbón, de A. Gil y Zárate, y protagonista de un gran número de novelas folletinescas, como La cabeza del rey don Pedro, de M. Fernández y González.

${ }^{13}$ J. I. Ferreras, El triunfo del liberalismo y de la novela histórica (1830-1870), Madrid, Taurus, 1976, p. 99.

${ }^{14}$ Algunos títulos son: El doncel de Don Enrique el Doliente, de Larra, o El gabán de Don Enrique el Doliente, de J. Muñoz Maldonado.

${ }^{15}$ Sobre todo su valido, Beltrán de la Cueva, fue protagonista de diversas obras como las de M. Fernández y González o L. de Retes. 
el Cruel. Este último reunía todos los rasgos necesarios para acaparar la atención de los románticos; contaba con un carácter que lindaba con lo perverso y satánico, de hecho, algún estudioso ha referenciado su condición de enfermo mental ${ }^{16}$. Al mismo tiempo le rodeaba un ambiente conspiratorio desde el primer instante que reinó, alentado por personajes como Juan Alfonso de Alburquerque o los Padilla. Tenía un largo pasado romancesco plagado de leyendas. En el siglo XIx fue objeto de un debate historiográfico, convirtiéndose en símbolo del liberalismo: el centralismo reforzaba la unidad y Pedro fue su abanderado. Se había enfrentado a la Iglesia y a los nobles. Este último aspecto es relevante teniendo en cuenta la Monarquía Constitucional que se construye en la primera mitad del siglo. No obstante, vilipendiado, traicionado, no pudo desprenderse finalmente de la sombra de su verdugo.

Enrique II representaba el pasado feudal. Carecía del atractivo particular de Pedro, lo cual venía a contravenir el individualismo romántico. Arraigó a la imagen de cruzada ${ }^{17}$ su guerra fratricida, perfilándose como aliado de la Iglesia. Había introducido un elemento extranjero en la contienda, las compañias blancas, que encarnaban lo contrario al concepto romántico de la caballerosidad.

Su trayectoria literaria queda reducida a su primer reinado, con la guerra civil como fondo y, ligado a ella, el episodio de Blanca de Borbón.

Los hermanastros estarán unidos por un fatal destino, pues «la quiebra de la legitimidad monárquica rondó reiteradamente a lo largo del conjunto del reinado de Pedro I» ${ }^{18}$. Además, y así lo entendió la mayoría de escritores del siglo XIX, uno representaba el progresismo y el otro el conservadurismo, aunque hay autores ${ }^{19}$ que han cuestionado esta valoración.

El enfrentamiento que protagonizaron quedó inmerso e influido por la Guerra de los dos Pedros y por la Guerra de los Cien Años. De hecho, el episodio histórico ha sido entendido por algún estudioso como la primera guerra civil española ${ }^{20}$. La importancia de esta radicaba en el hecho de que «habían peleado la legitimidad frente

\footnotetext{
${ }^{16}$ G. Moya, Don Pedro el Cruel. Biología, política y tradición literaria en la figura de Pedro I de Castilla, Madrid, Júcar, 1974, p. 17.

${ }_{17}$ J. Valdeón Baruque, Enrique II de Castilla: la guerra civil y la consolidación del régimen (1366-1371), Valladolid, Universidad de Valladolid, 1966, p. 57.

${ }^{18}$ J. M. Nieto Soria, «La monarquía como conflicto de legitimidades», en J. M. Nieto Soria (dir.), La monarquía como conflicto en la corona castellano-leonesa, Madrid, Sílex, 2006.

19 J. Valdeón Baruque, Los Trastámaras. El triunfo de una dinastía bastarda, Barcelona, Temas de Hoy, 2006. Este autor apoya su tesis en el hecho de que las ciudades más prósperas de la Meseta apoyaron a Enrique.

${ }^{20} \mathrm{~J}$. Valdeón Baruque, Pedro I el Cruel y Enrique de Trastámara. ¿La primera guerra civil española?, Madrid, Aguilar, 2002. Este autor rebate a C. Viñas, pues considera la contienda como guerra civil castellana.
} 
a la bastardía, acompañada esta última de una desdichada nota de ilegalidad, a la vez que de infamia $»^{21}$. De esta manera, Pedro no había ejercido su soberanía dentro de los límites de la legalidad, mientras que Enrique recibía la legitimidad de la Iglesia y de las Cortes ${ }^{22}$. Así pues, Enrique II quiso derrocar la legitimidad de ejercicio de Pedro alegando al concepto de tiranía. Al mismo tiempo desacreditaba con la invención de alguna leyenda la legitimidad de origen. Con ello también conseguía presentar a Pedro como enemigo de la Iglesia y del pueblo, consecuencia del antisemitismo que usó en su propaganda. Enrique II de Castilla se presentaba como libertador del pueblo; el regicidio será presentado como tiranicidio y quedará justificado por el providencialismo ${ }^{23}$.

Sobre todo «simbolizó Pedro Ino sólo el más sobresalienteconato decentralización del poder real, sino la impugnación del principio hereditario de la monarquía» ${ }^{24}$. De hecho, esto supuso un problema para Enrique II, puesto que «necesitaba conservar para sus sucesores el régimen hereditario; pero debía interpretarlo de modo que la elección en sus circunstancias fuera justificable» ${ }^{25}$.

Otro aspecto debatido sobre el reinado de Enrique iI fueron las mercedes enriqueñas, aunque hay autores que sostienen que empobrecieron al pueblo ${ }^{26}$, lo cierto es que el sector que más privilegios consiguió fue la nobleza de servicio ${ }^{27}$. Para otros, sin embargo, reforzó los privilegios de los nobles ${ }^{28}$.

No obstante, a pesar de la hegemonía hispánica que alcanzó Castilla con él y la consideración por parte de algún autor de que era un rey popular ${ }^{29}$, su protagonismo quedó reducido al de su hermanastro.

Usurpador, codicioso, traidor, así lo calificaba Joaquín Guichot ${ }^{30}$, que, ferviente defensor del rey Pedro, llega a negar el asesinato de Blanca de Borbón. Por otro lado, Modesto Lafuente entenderá que los métodos de Pedro no eran los adecuados, pero no duda en resaltar su labor como legislador. Admite en relación a los nobles que

\footnotetext{
${ }^{21}$ Ibidem, p. 232.

${ }^{22}$ Ibidem, p. 243.

${ }^{23}$ C. Valdaliso Casanova, «La legitimación dinástica en la historiografía Trastámara», Res publica, 18 (2007), pp. 307-321.

${ }^{24}$ P. Cirujano Marín, Teresa Elorriga Planes, Juan Sisinio Pérez Garzón, ob. cit., p. 103.

${ }^{25} \mathrm{~J}$. Gimeno Casalduero, La imagen del monarca en la Castilla del siglo XIV, Madrid, Selecta Revista de Occidente, 1972, p. 111.

${ }^{26}$ G. Moya, ob. cit., p. 144.

${ }^{27}$ J. Valdeón Baruque, Enrique II de Castilla: la guerra civil y la consolidación del régimen, ob. cit., p. 302.

${ }^{28}$ G. Moya, ob. cit., p. 57.

${ }^{29}$ J. Valdeón Baruque, Enrique II de Castilla: la guerra civil y la consolidación del régimen, ob. cit., p. 84.

${ }^{30}$ J. Guichot, Don Pedro I de Castilla, Sevilla, Colección de Clásicos Sevillanos, 2011, p. 49.
} 
apoyaron a Enrique que «no había un pensamiento noble [...] limitaban sus aspiraciones a derrocar de la privanza a una familia ${ }^{31}$. Impulsado por el mesianismo y apoyado por el pueblo, Enrique se convirtió en el libertador. De esta manera lo exponía Beltrán Du Guesclin: «[...] echaremos del mundo un tirano, un terrible monstruo que en figura humana está en la tierra [...] restituirás a tu patria y al nobilísimo reyno de tu padre la libertad $»^{32}$.

\section{Enrique it de Castilla en la literatura romántica}

En primer lugar vamos a analizar la presencia de este personaje en el drama, atendiendo a las siguientes obras: Don Enrique el Bastardo, conde de Trastámara, de Pedro Sabater; Don Enrique el dadivoso o el zapatero y el rey (tercera parte), de Víctor Balaguer; Blanca de Borbón, de José Espronceda; Blanca de Borbón, de Antonio Gil y Zárate; La verdad vence apariencias, de Gertrudis Gómez de Avellaneda; Enrique de Trastámara o los mineros, de Marcel Francis Cornu.

Debemos de precisar que el análisis exhaustivo lo haremos en las dos primeras obras citadas porque es donde tiene cierto protagonismo Enrique II.

Empezaremos pues por el drama histórico de Pedro Sabater ${ }^{33}$. Esta obra supone casi una excepción dado que el autor se posiciona al lado de Enrique.

En el primer acto se describe a Pedro con todos los matices crueles con los que la Crónica de López de Ayala lo perfiló. De esta manera, e instigado por Samuel Leví, le vemos preparar el secuestro de Juana de Manuel, lo que sin duda constituirá el motor de la trama. Juana se nos revela como un personaje con ciertos tintes románticos; siente la soledad, huérfana presa de una infausta estrella. En el acto segundo Enrique se halla en el castillo de Juana. Es entonces cuando se plantea el aparente conflicto romántico: debe decidir entre el amor y el deber: « $i$ queréis que sepultado en este oscuro desierto me tenga el vulgo por muerto y el hidalgo por menguado?» (II, 1, p. 22). Enrique se siente libertador del pueblo: « $₹ Y$ vos Doña Juana, podréis consentir que luche Castilla clamando por mí, y débil mi brazo rehúya la lid?» (II, 1, p. 25). En el acto tercero se reúnen en el convento de San Juan del Espinar diversos nobles para apoyar a Enrique, entre los cuales se encuentra Diego López de Ayala, quien alude al

\footnotetext{
${ }^{31}$ M. Lafuente, Historia General de España desde los tiempos más remotos hasta nuestros días, parte II, libro III, Madrid, Establecimiento Tipográfico de Mellado, 1852, p. 197.

${ }^{32}$ J. de Mariana, Historia General de España, libro xvII, cap. VII, Valencia, Oficina de Don Benito Monfort, 1790, p. 175.

${ }^{33}$ P. Sabater, Don Enrique el Bastardo, Conde de Trastámara, Valencia, Imprenta de López y Compañía, 1841.
} 
providencialismo. El héroe se siente preso del fatal sino pero es el elegido para reinar: «[...] no quiero la corona... sus diamantes se avienen mal con mi fortuna infausta, y ponerla en mi frente maldecida fuera abatirla más, fuera mancharla» (III, 2, p. 34). Se sucede entonces una escena en ambiente sepulcral impregnada de patriotismo, el efecto sublime horroroso que debiera aportar la conjura y que permitiría a este drama ser romántico es inexistente. En el acto cuarto se justifica el motivo de la rebelión, lo que supone una lección histórica relativa a la función del rey: «Que cuando rompe la ley el que en el trono se asienta, será vil el que consienta tregua o descanso a tal rey» (IV, 3, p. 44). El monarca no ejerce como buen soberano, además, ni tan siquiera tiene legitimidad de origen: «Rey Don Pedro una es la sangre que nos alienta a los dos, mas jah! la mía está pura, la vuestra se mestizó» (V, 7, p. 78). El último acto, dedicado a la tragedia de Montiel, destila cierto efectismo romántico con la alusión al cantar melancólico de los religiosos que confunde a Juana, la cual espera suicidarse con un brebaje si perece Enrique. Pero todo quedará reducido a un pequeño susto: es Pedro quien ha muerto. El autor omite el final del rey con la clara intención de salvaguardar la imagen de Enrique.

Estamos en realidad ante un drama que carece de verdad histórica. Estos dramas se decantan por el material legendario. Ello contribuye a que el autor pueda exponer su ideología. Enrique se transforma en libertador de un pueblo oprimido por un rey tirano. El drama expresa, tal y como señalara en 1830 Martínez de la Rosa en Apuntes sobre el drama histórico, la utilidad de la historia con elementos trágicos. Además, no olvidemos que «el Romanticismo liberal introdujo a través del drama histórico el compromiso político ${ }^{34}$. En este sentido la muerte del rey Pedro es justa porque en estos tipos de dramas los personajes históricos son públicos y a sus actuaciones particulares se atribuye ejemplaridad colectiva ${ }^{35}$. El autor refleja en el drama la propia inestabilidad de su presente: en 1841, entre otros sucesos, hubo un intento de secuestro de la heredera por parte de Diego de León.

El autor sigue la estela de Juan de Mariana para atacar la conducta del rey Pedro, resaltando su tiranía, veleidad, incluso, su ilegitimidad de origen.

En el drama de Víctor Balaguer ${ }^{36}$ podemos apreciar ya desde el título, en clara alusión a las mercedes enriqueñas, la imagen hostil del personaje que dará el autor. En este drama Enrique no comparte escena con Pedro. De hecho, la obra supone la continuación del drama romántico de Zorrilla, El zapatero y el rey. La pieza surge en el contexto de los

\footnotetext{
${ }^{34}$ E. Caldera, El teatro español en la época romántica, Madrid, Castalia, 2001, p. 98.

${ }^{35}$ K. Spang, El drama histórico. Teoría y comentarios, Pamplona, Eunsa, 1998.

${ }^{36}$ V. Balaguer, Don Enrique el Dadivoso o el Zapatero y el rey (tercera parte), Barcelona, Imprenta de Roque Gallifa, 1840.
} 
primeros pasos del sistema liberal, iniciándose la regencia de Espartero. Referenciamos el contexto porque la obra no va a estar exenta de implicaciones ideológicas. Blas Pérez, personaje novelesco, será el portavoz del liberalismo, vengador del rey Pedro. Así, dice: «Noble me hizo y caballero, a los grandes me igualó, y a tal altura elevó al hijo de un zapatero» (Prólogo, 5, p. 19). Enrique es un rey cobarde, ambicioso, que ansía vengarse de Blas, el zapatero, por medio del capitán Hugo, verdadero héroe romántico. El conflicto con el universo se genera mediante la trama amorosa: el héroe, leal a Enrique, ama a la hija de Pedro. Después se describe al rey como supersticioso y clasista: «Que aunque hayáis el guante alcanzado nunca a su rey se ha igualado el hijo de un zapatero» (Prólogo, 7, p. 23).

La pareja de enamorados protagoniza escenas plagadas de lirismo. La diferencia de bandos impide que se amen, de ahí surge la ruptura del yo con el mundo, sobre todo cuando revela su identidad. Así, alude a la soledad: «[...] yo, paloma abandonada sola cruzo el aire errante, de todos soy olvidada» (Prólogo, 9, p. 27). En el acto primero el rey se lamenta de la corrupción de la corte. El rey en este periodo intentaba recortar los privilegios: «[...] Harto me fatiga ya esa turba cortesana [...] es la corte fementida, mar revuelto de ambición» (I, 1, p. 35). Lo sublime horroroso se da a través de las conjuras. Recordemos que una conspiración cívico-militar será la que hará caer a Espartero. La obra refleja la mirada progresista del autor y una exaltación de la unidad del pueblo. Enrique es un héroe romántico, pues vive atormentado por los remordimientos: «[...] ¿Qué vale un cetro, un trono [...] si en el lecho donde apoyo mi cabeza puñal oculto su armazón encierra?» (I, 2, p.38). La palabra fratricida persigue al personaje. Mientras, se suceden los lamentos de la heroína romántica, la alusión a la juventud marchita, a la pasión de un corazón ardiente. Finalmente, en el acto tercero, rodeado de augurios y pesadillas Enrique morirá ante Blas, arrepentido por su ambición. Como héroe romántico no pudo escapar al fatal destino: «[...] ¿acaso crees que en mi ciego encono de mi ambición las glorias ya olvidadas no siento resbalar mi pie del trono?» (III, 15, p.97). El zapatero consiguió vengar a su popular rey: «La mancha borré del trono que un hombre en él imprimió» (III, 16, p. 100).

El drama tiene elementos románticos: la escenografía lúgubre, como la Selva de la Cruz, los augurios, el sentimiento irónico de fatalidad, de cataclismo universal, hay ruptura con el universo en la pareja de héroes Sol-Hugo aunque hallarán la felicidad gracias al final trágico del personaje histórico principal, Enrique II, determinado ya por la Historia. El autor convierte a Blas en altavoz del liberalismo, y por ende, hace una defensa de la legitimidad del rey Pedro, además, tergiversa un tema legendario como es el Romance de los Borceguíes para hacer vengador a un zapatero, considerándose al Trastámara paladín de la nobleza, es toda una revelación ideológica. 
A continuación trataremos una tragedia cuya protagonista es Blanca de Borbón, nos referimos a la obra de Antonio Gil y Zárate ${ }^{37}$. Haremos un análisis sucinto debido a que Enrique no es el protagonista principal y a que se trata de una tragedia clásica. Tendrá, pues, una finalidad didáctica. Por ello, el contexto en el que se escribió y estrenó la obra es relevante; se escribió en $1825^{38}$, obra de un exiliado liberal, y fue estrenada en un ambiente de inestabilidad política con la guerra carlista de fondo y la regencia de María Cristina. No obstante, hemos decidido comentarla porque recoge un episodio clave en la pugna fratricida. Además, consideramos que el drama romántico está relacionado con la trágica neoclásica, como ha señalado Rusell. P. Sebold ${ }^{39}$.

La tragedia se inicia con las revueltas protagonizadas por Enrique para liberar a la reina madre de Castilla. Se describen las facciones entre los nobles, sus ambiciones. El rey ha olvidado sus funciones como soberano anteponiendo sus caprichos. Los personajes trágicos están perfilados con grandiosidad; Blanca se rebela contra su destino: «No, caballeros, no, nunca mi nombre a discordias civiles dé pretexto» (I, 3, p. 14). La imagen que se nos ofrece de Enrique no es del todo positiva porque aprovecha la causa de Blanca para fines particulares: «[...] que a los inicuos reserva el mundo perdurable infamia [...] Yo, en tanto, pura mi fama dejaré» (IV, 8, p. 69). El rey don Pedro es digno de compasión porque el destino le empuja a ser cruel: «A ser me arrastran cruel a mi pesar cuando el designio forman de separarnos» (IV, 9, p. 69). Más tarde, atormentado, dudoso, admitirá que es esclavo de su fiero anatema, por tanto, Blanca morirá.

El autor exalta la actitud reprochable del rey, quizás aludiendo a la de Fernando VII, pero lo exculpa porque le hace preso de su propia naturaleza y del entorno ambicioso que le rodea. En la tragedia prima el fin didáctico.

En la obra de Espronceda ${ }^{40}$, escrita como exiliado liberal sobre 1831-1832 ${ }^{41}$, se aprecian rasgos románticos en la maga y su hijo. Este último, ser demoníaco, será el asesino de Blanca, inspirado por los celos de María Padilla. Esto supone una exculpación del rey Pedro. Ambos carecen de la grandiosidad trágica, no se rebelan contra el destino. Enrique adquiere rasgos de caballerosidad: «[...] El nombre de traidor que me designan es para mí un blasón [...] ¡ah! Si es forzoso para salvarte

\footnotetext{
${ }^{37}$ A. Gil y Zárate, Blanca de Borbón, Madrid, Imprenta de José María Repullés, 1835.

${ }_{38}$ P. Menarini, P. Garelli, F. San Vicente, S. Vedovato, El teatro romántico español (1830-1850). Autores, obras, bibliografía, Bologna, Atesa, 1982, p. 48.

${ }^{39}$ R. P. Sebold, La trayectoria del romanticismo español, Barcelona, Crítica, 1983.

${ }^{40}$ J. de Espronceda, Blanca de Borbón, Alicante, Biblioteca Virtual Miguel de Cervantes, 1999. Publicación original: Madrid, Imprenta de M. Rivadeneyra, 1870.

${ }^{41}$ P. Menarini, P. Garelli, F. San Vicente, S. Vedovato, ob. cit., p. 42.
} 
arrebatar su vida, quiero añadir al nombre de rebelde el título de fratricida» (I, 4, p. 8). Es una tragedia clásica que carece de fin aleccionador porque despunta lo legendario, afín a lo romántico.

La obra de Gertrudis Gómez de Avellaneda, La verdad vence apariencias ${ }^{42}$, muestra cierto eclecticismo, estando en la línea del tipo de dramas que describe E. Allison Peers y que aúnan clasicismo con Romanticismo ${ }^{43}$. La propia autora reconoce haberse inspirado en Lord Byron, de hecho, la temática es romántica.

El sentido irónico del tiempo y del fatalismo es básico en la obra. El tema principal gira alrededor de una maldición familiar que guarda relación con la ambición. Una noche de 1367 confluyen en un castillo diversos personajes. En un ambiente de confusión es asesinado D. Tello, privado del rey Pedro. El acto primero comienza en 1371; Enrique ya es rey; Rodrigo se va casar con Leonor en el tercer aniversario del trágico suceso. Entonces se revelan las identidades. Los equívocos se suceden: el padre sentencia al hijo errado pero será salvado a tiempo. Como el rey advierte: «Falsa apariencia siempre miráis al juzgar» (II, 13, p. 93). El drama es romántico, pero el final es ecléctico y lo que subyace es una lección al estilo de las comedias áureas. El papel otorgado a Enrique resulta paradójico porque se erige justiciero en una trama que tiene mucho que ver con su propia verdad histórica.

Por último queremos mencionar brevemente un drama romántico escrito por el francés M. Francis, Enrique de Trastámara o los mineros ${ }^{44}$, acomodado a la escena por dos autores españoles, por ello se escapa de los límites de nuestro estudio. La reseñamos porque en ella, tal y como anuncia el título, se presenta a Enrique como un rey popular. Se destaca su prudencia. La obra tiene como tema el honor. El Trastámara se une solidariamente con los mineros porque se siente identificado; al igual que Mendo él también sufre una afrenta familiar. Se apela a la generosidad y unidad del pueblo frente a la crueldad del Merino.

Atenderemos ahora al tratamiento del rey en las siguientes novelas: El Puñal del Trastámara ${ }^{45}$, de Manuel Torrijos, y su segunda parte, Justicias del rey Don Pedro; El bastardo de Castilla (segunda parte de Men Rodríguez de Sanabria), de Manuel Fernández y González; Don Pedro I de Castilla o el grito de venganza, de D. Víctor África Bolangero.

${ }^{42}$ G. Gómez de Avellaneda, La verdad vence apariencias, Madrid, Imprenta de D. José María Repullés, 1852.

${ }^{43}$ E. A. Peers, Historia del movimiento romántico español, Madrid, Gredos, 1973, p. 77.

${ }^{44}$ M. F. Cornu, Enrique de Trastámara o los mineros, Madrid, Imprenta de D. Joaquín Merás y Compañía, 1843. Acomodado a la escena española por Carlos García Doncel y Luis Valladares Garriga.

${ }^{45} \mathrm{M}$. Torrijos, El puñal del Trastámara, Madrid, Imprenta de Beltrán y Viñas, 1858; su segunda parte es Justicias del rey don Pedro, Madrid, Imprenta de Ducazcal, 1858. 
Enrique II prolifera en las llamadas novelas históricas de aventuras, las cuales suponen una paulatina desintegración del Romanticismo. Es en la década de los 50 cuando empiezan a abundar, periodo que apela a lo nacional. De ahí el subtítulo de original que llevan estas obras.

Las novelas de Manuel Torrijos son consideradas novelas de aventuras históricas ${ }^{46}$. Se trata de novelas folletinescas en las que se destaca la aventura y la esquematización de los personajes históricos, expresándose la ideología del autor, en este caso, favorable al rey Pedro, apoyado por el pueblo y rodeado de conspiradores. Entre los ambiciosos se halla Enrique. El puñal que pende de la cintura del conde es reflejo de su codicia: «[...] Este puñal que llevo a la cintura tiene que hundirse dentro de tu pecho; él será el que acabe con tu vida, él será el que me haga señor de tus dos reinos» (cap. XIX, p. 200). Frente a Juan Alfonso de Alburquerque, Men Rodríguez de Sanabria constituye la máxima expresión de la lealtad. En el capítulo vigésimo séptimo se describe la ruindad de los bastardos: la envidia hacia los Padilla justifica la rebelión. Acaba la novela despojando el leal Sanabria a Enrique de su simbólico puñal. En la segunda parte se inicia la novela en el contexto previo a la Guerra de los dos Pedros. Enrique trata de aliarse con Pedro de Aragón mientras vive obsesionado por el puñal: «[...] la sombra de Don Pedro me persigue por todas partes horrible y amenazadora» (cap. XXIV, p. 294). En el último capítulo se nos revela a Enrique como cobarde, Pedro le da el puñal para que lo mate pero aquel es incapaz. El rey le perdona mas muere a traición. En definitiva, el universo aparece como histórico pero carece de efectividad, de hecho, el propio título señala el material legendario del que se nutre la novela. Los personajes no evolucionan, sufriendo un proceso de esquematización, quedando divididos entre buenos y malos. La burguesía está ya asegurada. Este hecho propicia una cierta tendencia a tratar temas que contribuyan a fortalecer la identidad nacional. El mensaje que se transmite al lector es el de la lealtad, asociada a una imagen favorable del rey Pedro.

Con el Bastardo de Castilla ${ }^{47}$ nos hallamos ante una novela de folletín cuyo protagonista principal es Leila. Esta esconde su identidad bajo la apariencia del paje Gastón. La aventura gira alrededor del plan de venganza del personaje. Las implicaciones ideológicas del autor son constantes y favorables al rey justiciero. Enrique, codicioso, instigador, es el vengador de Leila, un ser despreciable que se complace en atormentar al rey Pedro con presagios funestos.

Hay que entender la novela dentro del contexto del reinado de Isabel II, con el

\footnotetext{
${ }^{46}$ J. I. Ferreras, Catálogo de novelas y novelistas españoles del siglo XIX, Madrid, Cátedra, 1979.

${ }^{47}$ M. Fernández y González, El bastardo de Castilla, Madrid, Ed. Tesoro, 1953.
} 
reforzamiento del centralismo, el liberalismo doctrinario y el nacimiento de la clase media. Un mundo corrupto, inestable y de camarilla rodea a la reina, de ahí el fin de una novela que exalte ya desde la primera parte la lealtad. Tanto en Men Rodríguez de Sanabria ${ }^{48}$ como en El bastardo de Castilla, el personaje histórico principal es un personaje histórico de segunda fila, lo que le permite interactuar con el universo y vivir cierta ruptura con él. El héroe se debate entre el deber y el amor, sufriendo en ocasiones incluso acusaciones del rey, sin embargo, su final será feliz. El personaje novelesco, de origen humilde, también se reintegrará en la sociedad porque al final se revela hija de Alfonso XI. Las intromisiones ideológicas del autor son constantes: señala que Pedro era un rey popular rodeado de conspiradores, heredero de una guerra civil. La novela conserva elementos románticos que se exageran pero carecen de contenido real. La verdad histórica no importa, prevalece el mensaje.

Hemos escogido la novela de Víctor África Bolangero ${ }^{49}$, catalogada como novela histórica de aventuras ${ }^{50}$, porque es afín a Enrique II, lo cual supone toda una excepción. Empieza la novela estando Alfonso XI en el lecho de muerte. El rey lamenta que vaya a reinar su hijo Pedro pero le pide al conde de Ledesma que le jure respeto. Aquel le entrega un anillo que luego contribuirá a que sea rey Enrique. El primer grito de venganza es ante la tumba de Leonor. La parte tercera refiere la batalla de Nájera y el castillo de Montiel. La propia María de Padilla es la encargada de defender a Enrique pues, aunque el destino que le espere a Pedro sea cruel, es justo: «[...] Pedro ignora que ese hermano al que llama cobarde y audaz es el encargado tal vez por la Providencia de hacerle expiar los crímenes» (parte III, cap. III, p. 395). Sin embargo, Enrique se siente desdichado: «[...] el hombre más desgraciado del reino tiene libertad para crearse en su imaginación los sueños más felices» (parte III, cap. x, p. 502). Cuando los hermanastros se enfrentan, el fiel Ledesma interrumpe, Enrique perdona a Pedro y el valido le hace entrega de la sortija. No obstante, el final del rey cruel está escrito: morirá a manos de Haffiz en venganza de su hermana Zulema.

La novela conserva del Romanticismo sólo la ambientación del universo, como es el empleo simbólico de ciertos objetos, la atrocidad de los actos, la supremacía de lo afectivo. Se falsifica la historia con una clara intención de defender la imagen de Enrique II, exculpándole de la muerte de Pedro, y se exaltan valores como la lealtad. El héroe principal es un personaje histórico secundario, el Conde de Ledesma, valedor de la legitimidad de Enrique II. El autor expone su opinión sobre el Trastámara: Enrique

\footnotetext{
${ }^{48}$ M. Fernández y González, Men Rodríguez de Sanabria, Madrid, Imprenta de Gaspar y Roig, 1853.

${ }^{49}$ V. África Bolangero, Don Pedro I de Castilla o el grito de venganza, Madrid, Imprenta de Don José María Repullés, 1857.

${ }^{50}$ J. I. Ferreras, La novela española en el siglo XIX (hasta 1868), Madrid, Taurus, 1987, p. 32.
} 
frenó la ambición de los nobles y fue un libertador ante tirano. La segunda parte de la novela, relativa ya al reinado de Enrique, gira en torno a un triángulo amoroso. La muerte del rey, ejecutada por Mahomet, tiene como instigadora a una amante del monarca, lo que supone la manipulación del Romance de los Borceguies. La novela acaba con un cuadro histórico en vindicación del rey Enrique.

Estas obras presentan rasgos afines con las novelas románticas, como el terror, el suspense o la presencia de protagonistas-antagonistas ${ }^{51}$.

Para concluir trataremos la figura del monarca en un romance histórico y una fantasía; El Fratricidio, de Ángel de Saavedra ${ }^{52}$, Los Borceguíes de Enrique Segundo, de José Zorrilla ${ }^{53}$.

En el romance de Ángel de Saavedra se hace una descripción al más puro estilo romántico sobre los últimos momentos de Pedro el Cruel, en un ambiente descarnado, tétrico, fantasmal. El rey vive atormentado por sus crímenes: «¡Ay que estoy nadando en sangre! ¡Qué espadas decís son esas!» (III, p. 35). El cuarto romance describe la lucha entre los hermanastros con ferocidad. El autor retrata al rey como el arquetipo de la perversidad. Busca el efectismo dramático del romance más que una exposición ideológica. Hay autores, sin embargo, que han querido ver en el retrato negativo del rey causas de índole privada del autor ${ }^{54}$, relativas a la nueva situación económica experimenta al heredar el ducado. El autor, no obstante, sigue la estela del Romancero, hostil al rey Pedro ${ }^{55}$.

La fantasía de Zorrilla ofrece una imagen nefasta de Enrique. En primer lugar se alude a las causas que destronaron al rey: la ayuda de los extranjeros y la traición de Enrique, que reina sin legitimidad. Así, se dice: «[...] a manos de una traición de serviles extranjeros, su matador don Enrique gozó en calma largo tiempo la corona de su hermano por la fuerza o por derecho» (p. 245). Luego viene la amenaza directa al bastardo pues: «[...] de la Voluntad de Dios incomprensibles secretos hay, mas donde van siempre juntos los castigos van los premios» (p. 245). A continuación se alude a las famosas mercedes enriqueñas La escena de la caza es simbólica, y al igual que el eclipse,

\footnotetext{
${ }^{51}$ E. Rubio Cremades, «Novela Histórica y folletín», en Anales de la Literatura Española, 1 (1962), pp. 269280.

52 Á. Saavedra, duque de Rivas, Romances Históricos, Alicante, Biblioteca Virtual Miguel de Cervantes, 2007; El pensamiento, periódico de Literatura y Artes, serie I, tomo I (1841), pp. 13-57.

${ }^{53}$ J. Zorrilla, «Los borceguíes de Enrique II», en Obras poéticas, París, Baudry, Librería Europea, tomo XXXIX, 1847, pp. 245-253.

${ }^{54}$ G. Moya, ob. cit., p. 314.

${ }^{55}$ Esto no quiere decir que no hubiera romances favorables al rey, de hecho Lope de Vega recoge algunos de ellos en sus comedias. Por otro lado, recordemos la existencia del Romance de los jaboneros, desfavorable a Enrique II.
} 
presagia el funesto final. El destino del rey, muerto envenenado, ha sido ejecutado por un antiguo amigo del rey Pedro, el moro Mohamad. Se establece así una especie de justicia poética.

Por último aludimos a una leyenda histórica que indirectamente es hostil a Enrique, El alcaide del castillo de Cabezón ${ }^{56}$, de Miguel López Martínez. El alcaide del castillo es símbolo de lealtad vasallática. Leal a Enrique protege el castillo con su familia y los soldados. Como Guzmán el Bueno, el alcaide sacrifica a su hija antes de rendirse. Hasta el rey Pedro admira su lealtad. El ataque a Enrique se manifiesta a través de la tropelía que ha cometido su tropa.

\section{Conclusiones}

La naturaleza del Romanticismo es compleja y en el caso español tiene la peculiaridad de que revertió en «una cultura arraigada en la visión mítica del pasado» ${ }^{57}$. Esto repercute claramente en el objetivo de nuestro estudio, dado que el personaje de Enrique II se va a politizar al igual que el de Pedro el Cruel, convertido en mito. El caso de Enrique in podríamos encuadrarlo dentro de lo que Vicente Llorens ${ }^{58}$ llamó medievalismo político, debido a su poca profusión en obras plenamente románticas.

La introducción de los personajes históricos en la literatura era una tarea difícil porque están determinados ya por la Historia y no pueden materializar ya la ruptura con el mundo salvo que el historicismo resida en el universo, de ahí que los escritores prefieran lo histórico-legendario. Esto es más fácil en el drama porque presenta mayor inmediatez y tiene un afán totalizador que en la novela es difícil de conseguir, lo cual favorece la colisión con el universo, que se consigue mejor cuando los personajes son controvertidos, como Pedro.

La corte intrigante y la guerra civil reflejaban la política de la época con la expresión de los estados humanos y anímicos, lo que hace a estos personajes idóneos para la novela. Pero el recorrido novelesco de Enrique in fue mucho más corto que el de Pedro el Cruel. Este está presente en novelas románticas ${ }^{59}$ que siguiendo la estela de Walter Scott lo sitúan en un segundo plano que le permite participar en el conflicto con el universo novelesco.

\footnotetext{
${ }^{56}$ M. López Martínez, «El alcaide del castillo de Cabezón», en Semanario Pintoresco Español, tercera serie, tomo II (1844), pp. 76-80, 84-85, 99-101.

${ }^{57}$ L. Romero Tobar, Panorama crítico del romanticismo español, Madrid, Castalia, 1994, p. 74.

${ }^{58}$ V. Llorens, El romanticismo español, Madrid, Castalia, 1989, p. 45.

${ }^{59}$ El primogénito de Alburquerque, de Ramón López Soler (1833) o El castellano o el Príncipe Negro en España, de Telesforo de Trueba y Cossío (1840), son algunos ejemplos.
} 
Cuando es protagonista adquiere los rasgos del héroe romántico. Esto es facilitado por su propia personalidad afín a la estética romántica y por la identificación que se hizo entre Romanticismo y liberalismo. Eligiendo pasajes oscuros pertenecientes a la esfera de lo privado podía el autor inventar lo que quisiera. Su personalidad se revelará en los momentos históricos cumbre.

No hay novelas románticas en las que Enrique II tenga cierta relevancia, por la propia estética del Romanticismo - influencia de la novela gótica, realista-social, costumbrismo - o porque su figura se halle vinculada al medievalismo político.

Es en la novela histórica de aventuras ${ }^{60}$ donde destaca Enrique II porque «si en todo género entra una dimensión ideológica, en la novela histórica se hace muy patente en la medida que se presenta como una reescritura de textos históricos previos» ${ }^{61}$. Estas novelas están más politizadas que las románticas porque el contexto en el que florecen es el de la construcción del Estado. Así se «acentúa en estas obras la Historia de España, intentando crear una memoria histórica» ${ }^{62}$. Todas las novelas analizadas apelan a lo nacional en sus subtítulos. El Estado Liberal ofrecía aquello que representaba el rey Pedro. Y, aunque el tratamiento de Enrique fue dispar, la tendencia fue dar una imagen negativa del Trastámara. La contienda era la expresión de determinadas formas de lucha de clase: trono y pueblo contra aristocracia. Además, el origen bastardo e ilegal de la dinastía no contribuía a reforzar la identidad nacional. Son novelas dramatizadas en las que abunda el diálogo, exaltándose valores como la lealtad o el linaje. Se apela a la conciencia histórica: esto es la agonía del Romanticismo, del cual sólo queda un universo no mediador y exagerado.

El corpus novelístico del artículo se sitúa en el reinado de Isabel II, con la afirmación de la burguesía nacional y el origen de la clase media y la industria folletinesca. La temática histórico-legendaria sufre un proceso de politización y Estas novelas conforman una sucesión de aventuras y una plataforma para que el autor exprese sus opiniones.

$\mathrm{Si}$ «la novela no es un género esencialmente romántico, sino, y más bien, todo lo contrario ${ }^{63}$, será fácil de entender el escaso protagonismo de Enrique II, un personaje que no resultaba romántico en comparación con Pedro.

La novela es más histórica que el drama y «el individuo histórico tiene carácter

\footnotetext{
${ }^{60}$ Enrique II también es protagonista de la novela de María Pilar Sinués La diadema de perlas (1857). Y comparte protagonismo con Pedro en Los dos reyes, de Juan de Ariza (1845).

${ }^{61}$ Celia Fernández Prieto, Historia y novela: poética de la novela histórica, Navarra, Eunsa, 1998, p. 37.

${ }^{62}$ J. I. Ferreras, El triunfo del liberalismo y de la novela histórica, ob. cit., p. 99.

${ }^{63}$ Ibidem, p. 175.
} 
dramático, cuanto más histórico sea y se concentren en él sus pasiones, más apto será para ser héroe principal ${ }^{64}$, lo que explica que Pedro ocupara el trono del drama romántico. Como personaje principal será un héroe romántico.

De los dramas estudiados solamente uno puede considerarse romántico. En él Enrique es un héroe romántico preso de los remordimientos. Se relata su final trágico por necesidad, ya que los auténticos héroes románticos logran un final feliz. Destacará en dramas eclécticos o históricos con elementos románticos o trágicos y un fin didáctico, contribuyendo al reforzamiento de la identidad de la nación.

El mayor protagonismo del rey Pedro en la literatura romántica se debe a factores políticos y estéticos. Entre los primeros cabe señalar que consideramos que sí hubo una identificación entre liberalismo y Romanticismo. Esto supuso la mitificación de Pedro como símbolo de la burguesía frente a Enrique. Este periodo es el coincidente con el triunfo álgido del Romanticismo. Ahora bien, en la década de los 50, cuando se intenta construir el Estado Liberal, Pedro por cuestiones ya no sólo estéticas sino políticas seguía resultando más idóneo.

Es cierto que la dinastía Trastámara logró la unificación estatal pero Enrique, aún precursor de la misma, era un bastardo fratricida. Fue además paladín de una corte intrigante y ambiciosa que bien podía ser ejemplo de la que rodeaba a la reina Isabel. Por tanto, el tratamiento de Enrique seguirá siendo negativo. Los temas de las obras resaltarán todos aquellos valores que contribuyan a afianzar la fidelidad a la nación, tales como la lealtad o la unidad. El moderantismo hizo que el tratamiento de Enrique fuera más dispar aunque en general fue negativo.

La trayectoria literaria de los hermanastros fue diferente por los motivos antes señalados; Enrique sufrió un proceso inverso al de Pedro, vilipendiado en las crónicas y el Romancero, fue considerado justiciero en las comedias áureas y, en general, bien tratado por la literatura romántica. La poesía culta ${ }^{65}$ fue arma propagandística para Enrique pero los románticos lo revelaron bajo su disfraz de libertador como un ambicioso usurpador.

No olvidemos la defensa que hizo Agustín Durán ${ }^{66}$, siguiendo la estela de

\footnotetext{
${ }^{64}$ G. Lukács, La novela histórica, México, Ed. Era, 1966, p. 121.

${ }^{65}$ Ó. Perea Rodríguez, «Propaganda ideológica pro-Trastámara en el Cancionero de Baena», en M. I. del Val Valdivieso, P. Martínez Sopena (dirs.), Castilla y el mundo feudal. Homenaje el profesor Julio Valdeón, II, Valladolid, Junta de Castilla y León, 2009, p. 587.

${ }^{66}$ Nos referimos al Discurso sobre el influjo que ha tenido la crítica moderna en la decadencia del Teatro Antiguo Español, y sobre el modo en el que debe de ser considerado para juzgar convenientemente de su mérito peculiar (1828).
} 
Nicolás Böhl, del teatro barroco, vinculando lo romántico al género español. Es verdad que hay ciertos elementos presentes en los dramas aquí estudiados que destilan barroquismo, como el sentido del honor, el celo justiciero o la fatalidad. Pero las obras aquí analizadas se sitúan, salvo las tragedias, en la década de los 40-50, tiempo en el que la burguesía «superados los entusiasmos del liberalismo de los años treinta, tiende a arrellanarse en el bienestar económico y en la tutela de ciertos valores tradicionales como patria, familia, sentido del deber» ${ }^{67}$. Estas obras sufren cierto eclecticismo. Se acercan al teatro nacional, histórico. En ellas, tal y como dijimos, es donde encontrará su lugar Enrique de Trastámara.

En definitiva, pensamos que en España sí hubo una identificación entre liberalismo y Romanticismo perdurable en el tiempo y mantenida dentro de tendencias liberales ${ }^{68}$. Esto explica el tratamiento negativo que se dio a la figura de Enrique II, pero sólo en parte.

Sobre todo los novelistas volcarán sus ideologías en sus obras porque «el Romanticismo francés que se defenderá en España permite sospechar que tanto el intelectual liberal, progresista y conservador utilizan la novela como vehículo doctrinario ${ }^{69}$.

Las novelas aquí referidas apelan al nacionalismo desde sus subtítulos; los dramas son más bien de índole histórico-nacional. Ambos géneros contienen expresiones ideológicas en su mayoría hostiles a Enrique, de lo que se infiere que tratándose de un periodo en el que se pretendía la construcción del Estado Liberal y la memoria histórica, se identificó ambas con Pedro el Cruel.

La historia de Enrique in en el Romanticismo es la historia del conde de Trastámara, porque a pesar de haber sido el fundador de la importante dinastía, era Pedro el símbolo del principio de heredad, básico en el reinado isabelino.

El rey Cruel arrebató el trono romántico a Enrique II como si por justicia poética aquella noche en Montiel el que hubiera quedado debajo a pesar de la ayuda de Beltrán Du Guesclin hubiera sido el Trastámara.

\footnotetext{
${ }^{67}$ E. Caldera, ob. cit., p.169.

${ }^{68}$ R. Navas Ruiz, El romanticismo español, Madrid, Cátedra, 1990, p. 49.

${ }^{69}$ I. M. Zavala, Ideología y política en la novela española del siglo XIX, Salamanca, Anaya, 1971, p. 60. 


\section{Bibliografía}

Abellán, J. L., Historia del pensamiento español. De Séneca a nuestros días, Madrid, EspasaCalpe, 1996.

Álvarez Junco, J., Mater Dolorosa, Madrid, Taurus, 2001.

CALDERA, E., El teatro español en la época romántica, Madrid, Castalia, 2001.

CARASA, P., «La memoria herida de Castilla y León. Introducción», en Pedro Carasa (coord.), La memoria histórica de Castilla y León, Valladolid, Junta de Castilla y León, 2003, pp. 7-11.

CARnero, G., «El teatro de Calderón como arma ideológica en el origen gaditano del Romanticismo español», Cuadernos de Teatro Clásico, 5 (1990), pp. 125-140.

Cirujano Marín, P., Perea Elorriaga, T., Pérez Garzón, J. S., Historiografía y nacionalismo español (1834-1868), Madrid, Centro de Estudios Históricos, 1985.

Díaz-Plaja, G., Introducción al estudio del Romanticismo español, Madrid, Espasa-Calpe, 1972.

Fernández Prieto, C., Historia y novela: poética de la novela histórica, Navarra, Eunsa, 1998.

FERRERAs, J. I., El triunfo del liberalismo y de la novela histórica (1830-1870), Madrid, Taurus, 1976.

, Catálogo de novelas y novelistas españoles del siglo XIX, Madrid, Cátedra, 1979. , La novela española en el siglo XIX (hasta 1868), Madrid, Taurus, 1987.

FLITTER, D., Teoría y crítica del romanticismo español, Cambridge, Cambridge University Press, 1992.

García CÁRCEL, R., La herencia del pasado (Las memorias históricas de España), Barcelona, Galaxia Gutenberg, 2011.

Gimeno Casalduero, J., La imagen del monarca en la Castilla del siglo XIV. Madrid, Selecta 44, Revista de Occidente, 1972.

Guichot, J., Don Pedro I de Castilla, Sevilla, Clásicos Castellanos, 2011.

Fox, E. I., «La invención de España, literatura y nacionalismo», en D. Flitter (coord.), Actas del III Congreso de la Asociación Internacional de Hispanistas, celebrado del 21 al 26 de Agosto de 1995, vol. IV, Birmingham, University of Department of Hispanic Studies, 1998, pp. 1-16.

LAFUENTE, M., Historia General de España desde los tiempos más remotos hasta nuestros días, tomo VII, Madrid, Establecimiento Tipográfico de Mellado, 1852.

Llorens, V., El romanticismo español, Madrid, Castalia, 1989.

LuKÁcs, G., La novela histórica, México, Era, 1996.

Mariana, J. de, Historia General de España, tomo VI, Valencia, Oficina de Don Benito Monfort, 1790. 
Menarini, P., P. Garelli, F. San Vicente, S. Vedovato, El teatro romántico español (18301850). Autores, obras, bibliografía, Bologna, Atesa, 1982.

Moreno Alonso, M., Introducción al estudio de la Historia en el siglo XIX, Sevilla, Servicio de Publicaciones de la Universidad, 1979.

Moya, G., Don Pedro el Cruel, Madrid, Júcar, 1974.

Navas Ruiz, R., El Romanticismo español, Madrid, Cátedra, 1990.

Nieto Soria, J. M., «La monarquía como conflicto de legitimidades», en J. M. Nieto Soria (dir.), La monarquía como conflicto en la corona castellano-leonesa, Madrid, Sílex, 2006, pp. 13-73.

PeERs, E. A., Historia del movimiento romántico español, Madrid, Gredos, 1973.

Perea Rodríguez, Ó., «Propaganda ideológica pro-Trastámara en el Cancionero de Baena», en M. I. del Val y P. Martínez Sopena (dirs.), Castilla y el mundo feudal. Homenaje al profesor Julio Valdeón, vol. II, Valladolid, Universidad de Valladolid, Junta de Castilla y León, 2009, pp. 587-600.

Romero Tobar, L., Panorama crítico del Romanticismo español, Madrid, Castalia, 1994.

Rubio Cremades, E., «Novela histórica y folletín», Anales de la Literatura Española, 1 (1962), pp. 269-280.

SEBoll, R. P., Trayectoria del romanticismo español, Barcelona, Crítica, 1983.

Spang, K., El drama histórico. Teoría y comentarios, Pamplona, Eunsa, 1998.

VAldaliso Casanova, C., «La legitimación dinástica en la historiografía Trastámara», Res publica, 18 (2007), pp. 307-321.

VALDEÓN BARUQUe, J., Enrique II de Castilla: la guerra civil y la consolidación del régimen (13661371), Valladolid, Universidad de Valladolid, Secretariado de Publicaciones, 1965.

- Los Trastámaras. El triunfo de una dinastía bastarda, Madrid, Temas de Hoy 2001. - Pedro I el Cruel y Enrique de Trastámara ¿la primera guerra civil española?, Madrid, Aguilar, 2002.

Zavala, I. M., Ideología y política en la novela española del siglo XIX, Salamanca, Anaya, 1971. 